\title{
Perception of future professionals of the construction industry of green building and architecture practices
}

\author{
Mikhail Leontev ${ }^{1, *}$ \\ ${ }^{1}$ Moscow State University of Civil Engineering, 129337, 26 Yaroslavskoe shosse, Moscow, Russia
}

\begin{abstract}
Green building as a new concept is gaining more and more value, acts as an important mitigating measure against the negative side effects of economic activity in cities. The implementation of the ideas and practices of sustainable development in the construction industry has led to the emergence of a new direction - environmental ("green") construction, which provides a much higher level of quality of facilities for constructed object. A study was carried out of the problems and prospects of green construction and architecture in cities. In this paper, the concept of green building and architecture is refined. The perception of green building and architecture practices by future construction industry professionals, the advantages and benefits of green building and architecture was investigated, factors that impede the implementation of green building in practice were identified. Currently, green building is little practiced for objective reasons. The practice of green building is hindered by a number of factors, for example, an unfavorable external environment in the form of policy or legislation, the economic situation in the country, negative market expectations, and lack of awareness. Health and increased productivity have been identified as the most important benefits of green building, followed by a reduction in the cost of construction and individual operations, and the conservation of natural resources. The recommendations addressed to non-governmental organizations, government bodies, professional communities are formulated.
\end{abstract}

\section{Introduction}

Human activities related to meeting his daily needs are exerting increasing pressure on the environment. For example, construction work, which is an important part of economic development, has a significant impact on the environment. The construction industry is responsible for the consumption of approximately $40 \%$ of natural resources and produces about $40 \%$ of all waste. Today, buildings around the world use about $40 \%$ of all primary energy consumed, $67 \%$ of all electricity, $40 \%$ of all raw materials and $14 \%$ of all drinking water supplies, and also produce $35 \%$ of all carbon dioxide emissions and almost $50 \%$ of all municipal solid waste [1].

\footnotetext{
${ }^{1}$ Corresponding author: miillen@rambler.ru
} 
The human environment (buildings) contributes to environmental crises due to depletion of resources, energy consumption, air pollution and the formation of waste. Up to ten different environmental impacts of construction activities have been described. These include, among other things, misuse of land, pollution of existing land, misuse of natural resources, and so on. In addition, the practice of on-site construction leads to a number of health and comfort disorders, especially for people living where construction work is underway. A problem that causes serious concern is that construction work causes about one third of environmental disasters [2].

For the first time, the need to change approaches to the construction of buildings and structures was talked about in Europe in the middle of 1980s, when the major energy crisis of the previous decade prompted a number of countries to take a course towards a global reduction in energy consumption, primarily in construction. Attention specifically to this industry was caused by the fact that large cities and megalopolises, in particular, individual buildings and structures, consume about half of the world's energy resources.

At the end of the $\mathrm{XX}^{\text {th }}$ century, the state of the environment began to cause serious concern. The unsatisfactory state of the environment in a number of regions was not least caused by rapid urbanization, accompanied by harmful emissions and a disturbance in the ecological balance in the biosphere. With the development of new technologies, standards of life quality began to change rapidly. The demands of the population on the level of organization of the urban environment today are much higher than 20 years ago $[3,4]$.

The described trends eventually led to the emergence of a new theory and practice of the organization of human life, called sustainable development. Sustainable development is a development that can satisfy current needs, but at the same time without compromising the capabilities of future generations [5]. The implementation of the ideas and practices of sustainable development in the construction industry has led to the emergence of a new direction - environmental ("green") construction, which provides a much higher level of quality of facilities under construction. The basis of environmental ("green") construction is the following: special, increased requirements for the comfort of buildings, a significant reduction in the consumption of natural resources by the object, as well as the absence of negative impact of the object on the people in it and the environment $[6,7]$.

Finally, the concept of an green building took shape in the 90 s of the XX century, when the question arose of the exact classification of such objects, the quantitative measurement of characteristics and the analysis of their combinations in a particular structure. Special voluntary certification systems for green buildings have been developed and introduced. Different national rating systems are used in world practice: the American LEED (the Leadership in Energy and Environmental Design - Guidelines for energy and environmentally acceptable design), the English BREEAM BRE Environmental Assessment Method - a method for assessing the environmental performance of buildings, developed in 1990 by a British organization BRE Global) and the German DGNB (developed by the German Sustainable Development Council - DGNB). Within the framework of these certification systems, a number of technical criteria have been developed that take into account the quantitative and qualitative characteristics of the comfort, energy efficiency and environmental friendliness of a building. Upon certification, a certain amount of points is awarded to the object - the more "green" characteristics, the more points and the higher the degree of "green" certificate issued as a result [8].

Thus, it is clearly seen that construction works have a direct impact on a person and his (her) environment, they lead to a change in the state's economy and the state of such an environment in terms of reserves and the quality of natural resources. An important question arises: how can we guarantee that construction work does not call into question the ability of the future generation to satisfy their needs? According to some authors, the most friendly way of interacting with the environment - do not carry out construction work [9]. 
However, without construction, life can become difficult and unprotected. This means that dynamic equilibrium is necessary, the production process must be friendly to the ecosystem, but at the same time competitive and not bearing other threats [10]. Sustainable buildings, commonly referred to as "green buildings", built according to the principles of sustainable development, are likely to meet the above requirements.

In this paper, the study of perceived problems and prospects of environmental construction practices was conducted. The following objectives were formulated:

1. identify events or phenomena that are associated with the concepts of green building and architecture, find out if there are conditions for the development of these areas in the construction industry.

2. clarify the concept and principles of green building and architecture, identify important requirements for buildings and structures that can be qualified as environmental construction objects.

3. find out whether green building and architecture will be faced with factors that impede its implementation in practice, determine the prospects or benefits of green building.

\subsection{Environmental construction and architecture}

Green building is a holistic approach to the planning, design and construction (repair) of capital buildings. It is included as an integral part of the wider concept of sustainable development, as it improves the environment and reduces the negative side effect of construction work. In addition, all obligations on materials, water and energy waste and pollutant emissions are converted into economic opportunities through the implementation of an environmentally friendly, healthier and cost-effective project. Concept of green building gives a clear answer to the urgent problems of health care, economics and environmental protection [11]. The construction of ecological buildings involves the building erection and the creation of a site taking into account the climate, the conditions on the construction site, cultural and social norms in order to reduce the consumption of natural resources, improve the quality and diversity of life. This is achieved by analyzing important and interrelated issues, such as the choice of the construction site and accounting of climatic features, the orientation and shape of the building, the lighting and thermoregulation system, building materials, combining all this into a unified project.

In other words, this is a general approach to quality management, in which from the very beginning of the project all key people involved at various stages of the project. This is necessary to achieve synergistic design through an interdisciplinary team work. Thus, the green building, as rightly notes C. Kilbert [2], is neither a combination of environmental components, nor a partial modification of the already developed standard building. This is not an architectural style in which a building should take a certain shape or have a "distinctive look". Rather, it is a philosophy of construction and architecture in which natural and resource-saving functions are included in the construction process. In addition, deliberate efforts are being made to improve the environment. One of the main distinguishing features of green building is that all professionals who will participate in the planning, design and construction of such a building should be involved in advance (at the design stage), for a professional contribution to the development of the project. This is done to achieve a synergistic effect. In addition to the key specialists who are usually involved in the implementation of ordinary construction projects, such as an architect, builders, engineers, and surveyor, in the case of environmental construction, other professionals are also needed who should be involved from the very beginning, for example, the land surveyor and the chief urban planner of the project [11]. 
As qualification reference book states, the land surveyor prepares draft resolutions on the issues of granting and withdrawing land plots, prepares for consideration the materials of the state land cadastre, taking into account the size of the plot, the quality of the land fund. The chief urban planner of the project carries out the direct development of territorial planning documents, urban zoning and planning documents for the territory. He (she) leads and directs the project team of urban planners, ensures its work; participates in the collection of source documentation necessary for the development of the project. He (she) carries out the necessary calculations and predictive modeling of the project. A landscape architect takes care of building site issues by taking measures that will improve the site, such as planning, placement and topography, which includes planting green spaces, as well as taking care of groundwater and chemicals. He (she) is also responsible for irrigation and planting, to protect against dust and soil from erosion.

Anyone can be argued that with the help of green building it is possible to maximize operational energy savings, ensure optimal healthy environment and limit the negative impact of construction activities. The role of professionals who usually participate in environmental construction is increasing significantly. For example, according to Chan A. et al., [1], an environmental construction project may require $40-100 \%$ more effort from the chief engineer or energy analyst. In addition to the role of the chief engineer in the development and execution of a conventional project, in green building, calculation of energy consumption and analysis of the life cycle of energy use is mandatory. However, this additional role is not limited to the chief engineer, all these professionals will perform analysis and calculations for the optimal design solution, taking into account the specific building. Regarding the choice of a construction site, with an emphasis on conservation and protection of cultural heritage, renovation of an existing building is preferable to a new building. When constructing a new building, an ecological building should always be built on a land plot that is in worse condition and not in better condition [12]. Therefore, the following options for construction sites should be considered first of all: with available sources of water resources, renewable energy sources, for example: biomass, solar and geothermal energy.

On the other hand, ecologically sensitive lands, agricultural lands, lands of historical or cultural significance, open spaces, or places exposed to dangers, for example: floods, fires, landslides are not suitable for ecological construction. The materials that will be used for environmental construction should ensure the achievement of sustainable development. All this also applies to the actual construction of the building.

\subsection{Some advantages of green building}

Many benefits related to green building were noted, among which the following stand out:

1. Environmental benefits for all: the benefits of green building do not end with residents and owners who are in a pleasant environment and pay less for utilities. The whole society benefits from the fact that ecological communities reduce pollution and conserve our natural resources, which leads to what is called environmental development.

2. Reducing water consumption by up to $50 \%$ by organizing a closed cycle of water use.

3. Reduced driving needs: reduced consumption of industrial oils, greenhouse gas emissions, and other pollution from vehicles by up to $50 \%$ compared to normal growth.

4. Keeping forests safe and sound: Recycling timber from old buildings using materials made from agricultural waste and buying timber from sustainable forests helps reduce their depletion.

5. Reduction of pollutants in waterways: storm drains that drain water from roofs of buildings, driveways and hard surfaces are the main cause of pollution of coastal waters and 
the closure of beaches. Surrounding houses with permeable surfaces, such as green spaces, canals overgrown with grass, allow rainwater and oil products to seep into the ground instead of waterways, and the placement of ecological buildings in previously developed areas prevents the spread of water pollution.

6. Financial and economic benefits. Ecological construction provides financial benefits and advantages in the form of saving energy and water resources. Reducing the amount of waste, improving the quality of the environment in the premises, increasing the level of comfort / productivity of employees, reducing the cost of maintaining the health of employees and reducing the cost of operational needs.

7. Energy: energy costs are a significant cost item in construction; they can be reduced by energy efficiency measures and related measures. A detailed review of the LEED rating system shows that ecological buildings, compared to conventional ones: on average, $25-30 \%$ more energy efficient; characterized by lower peak power consumption (economical fixtures, etc.); provide more chances to purchase network electricity produced from renewable energy sources (environmentally friendly and / or renewable certificates).

8. Health and productivity benefits: environmental construction is not only energy, but also about health, comfort and productivity in addition to the environment. People spend up to $90 \%$ of their time indoors, and the concentration of pollutants in a room is usually higher than outside, sometimes 10 or even 100 times $[6,13]$.

9. In this regard, the use of green buildings by people has become a necessity, because a healthy, comfortable home is an integral part of life. Environmental buildings typically have a healthier and more satisfactory working environment for tenants. Studies have shown that people working in a comfortable atmosphere increase productivity. Ecological buildings use carpets, paints, wall coverings and adhesives that emit little potentially volatile organic compounds that can cause eye and lung irritation, and other health problems. The construction of green buildings is closely linked to environmental architecture issues.

\subsection{The main features of environmental architecture}

The main feature of ecological architecture is respect for nature. But in a narrow sense, environmental architecture involves a combination of style attributes, the presence of visual attributes.

The following principles of environmental architecture were proposed:

1. The principle of conservation of energy.

The design of new buildings and the construction of new structures should be carried out in such a way as to minimize the need for the consumption of thermal energy for their heating or cooling.

2. The principle of reducing the volume of new construction.

From time immemorial, the builders used old buildings or only the material from their dismantling for the construction of new buildings. By the middle of the 20th century, a different approach seemed to prevail - the builders were convincing the city authorities and private investors that it was cheaper and more efficient to break everything and build from scratch is cheaper and more efficient. In reality - not always cheaper, rarely - more efficient, but it's easier.

3. The principle of "cooperation" with the sun.

In order to save money and environmental friendliness in ecological architecture, solar panels, solar energy storage devices are used. Also, the windows are located mainly on the south side of the building, which in total can give up to $80 \%$ savings on heating and hot water.

4. The principle of respect for an inhabitant. 
This is a significant change in the approach to the functioning of a building, when both a builder, an architect, and an owner see corporate ownership in the building, in which every inhabitant plays an important role. Obviously, the role of an inhabitant cannot be significant in multi-unit and multi-storey blocks with an unchanged configuration of the walls and roof, where the role of inhabitants is reduced mainly to the prevention of vandalism. But during the reconstruction of old buildings, the role of future inhabitants can be extremely large.

5. The principle of respect for the place.

To the greatest extent, this attitude of consciousness is represented in Eastern philosophy, in which merging with the natural environment, endless peering into it from time immemorial has been considered the highest value. In general, the European consciousness has long cultivated a different attitude towards nature. The nature was considered exclusively as a resource, as an object of purposeful human activity. The advent of environmental architecture gives the message that humanity is gradually trying to learn how to coexist with nature in harmony.

6. The principle of integrity.

It is this principle that expresses the ideal of ecological architecture, the desire for this ideal is increasingly painted actions of architects in countries where the greatest understanding between the new avant-garde and the customer [17].

While in Europe there are already thousands of ecological buildings, in Russia there are not many objects certified according to LEED - the system of certification of energyefficient buildings. The topic of environmental architecture is today being discussed very broadly, including at the government level, where decrees are adopted on the mandatory introduction of innovations in everyday building practice.

How do you really makes investors to spend on green technology? As it turned out, humanistic principles themselves do not work here, the ideas of environmental friendliness and energy efficiency appear in their projects after an investor decided to upgrade the class of the object. So there appeared energy-saving ventilation and air conditioning systems, and partial use of secondary water, and control of the degree of air pollution in parking lots, and the use of a green roof and vertical landscaping.

In an aggressive environment and not always a safe ecology of megalopolises, the comfort of architectural decisions can become the main argument for green architecture. Moreover, all interested parties: investors, architects, environmental experts agree that innovation will take root in Russia for a very long time, and this process is hardly worth forcing. The main thing is that precedents are created, and energy-efficient objects that are successful from the point of view of architecture appear [9].

The development of ecological construction should take place in the following areas: 1) dissemination of knowledge and information, i.e. promoting the need for such changes; 2) education, i.e. competency-based training of personnel to participate in this process.

In connection with this, a frequently encountered term is "green" vocational education and training: it includes economic, environmental and social aspects and promotes sustainable development, forming "green" competencies within the framework of formal, informal and spontaneous professional training [15].

Despite the fact that in Russian specialized sources, the terms and concepts "green" skills, "green" jobs, a "green" economy are already quite common, in the Federal Standards for Higher Education there are no references to them or references to competencies in the field of "green" technologies. Perhaps this is due to the fact that, as mentioned above, the equivalent of the term greening has not yet been found. 


\section{Materials and Methods}

In this study, a descriptive semi-structured questionnaire was used, the survey involved masters of several areas of training, they are future construction industry professionals (architects, builders, surveyors, urban planners), they was studying in Moscow State University of Civil Engineering, in approximately equal proportions. Interviewed respondents with experience in the profession for at least two years, aged 21 to 32 years, many had experience in project teams. The main research tool used is a semi-structured questionnaire containing closed questions with suggested answers, measured on a Likert scale.

To clarify some survey data, interviews were conducted with some respondents. A total of 62 questionnaires were sent out, and 52 were returned with answers, which corresponds to the response rate of $84 \%$, and was analyzed. Using the questionnaire, significant information was obtained on the practice, problems and prospects of green building and architecture in the context of sustainable development in the construction industry based on the experience of respondents. Collected data included respondents' understanding of the purpose and practices of sustainable development, green building, work in development teams of green projects, practical problems of green building and architecture, the benefits arising from it, the level of importance attached to the benefits and awareness of the concept of green building.

\section{Results and Discussion}

Data were obtained from the survey.

Three questions had to be assessed to establish the need for green building.

Three questions were subject to assessment, in order to clarify the implementation of the principles of sustainable development in construction.

1. How has the concept of sustainable development influenced professional activities?

2. What is the most important issue related to sustainable development?

3. What is the simplest, most easily implemented change that can be made in the professional sphere to limit the consumption of natural resources?

In Question 1, there was an increase in attention to the collection, processing and disposal of waste, the introduction of devices to save electricity in homes, the design of residential buildings to ensure sustainable development, - all this was considered as key impacts. In general, respondents' answers showed that knowledge of the laws of sustainable development affects their personal and professional lives and their understanding of the mutual influence of sustainable development and professional activity has become more complex over the past two years.

The answers to the second question were dominated by the idea of educating people to be aware of their actions and the impact that they may have on future generations. Sustainable development refers not only to environmental protection, but also takes into account social and economic issues.

Answering the third question, the respondents pointed to the social aspects of sustainable development, such as the purchase of locally produced goods, saving energy in homes by insulating walls / roofs and appliances that save energy, the priority use of public transport, recycling and automated waste recycling.

The following questions touched on green building and architecture.

Fourth, the respondents tried to find out how seriously the side effect of construction activities on the environment, which will contribute to the actualization of the practice of "green" construction. The answers were as follows: "yes" - 43 (83\%); "no" - 7 (13\%).

What impact do construction work have on the Russian environment? 
The answer "negative influence" (93\%) prevailed. Respondents believed that conventional construction negatively affects the environment, leading to: excessive consumption of natural resources, materials, energy, hazardous pollution (toxic waste, air and water pollution); there are dangers to public health and the problems of safe operation of buildings adjacent to construction sites. The landscape is changing, natural resources are being depleted. At the same time, only $7 \%$ of respondents said that there is no negative influence.

Further, among the conditions for environmental construction is the choice of a construction site. It is recommended that the construction sites for environmental construction be in worse condition, but these should not be abandoned industrial zones, but they are buildings on a free plot within an established urban area. The survey results indicated that $84 \%$ of 52 respondents answered "no" (disagree) to the question that deliberate efforts are being made to select construction sites that are in the worst condition for environmental construction. While 16\% answered "yes" (agree). This shows that one of the criteria for environmental construction has not been met.

Another very important condition for the practice of environmental construction is that each member of the project team is involved in the development in order to achieve a synergetic effect. In this regard, respondents were asked whether they are suitable for work in a team of an environmental construction project.

The results indicate that $95 \%$ of the professionals did not participate in the work of the project team of environmental construction, which means that the question of participation in environmental construction did not exist.

The prospects and benefits of environmental construction and architecture were identified by the survey, the most important factors were assessed by focusing on some of the benefits, such as lower capital costs, conservation of natural resources, health and increased labor productivity, etc. The results are presented in details in Table 1.

Table 1. The prospects and benefits of environmental construction and architecture.

\begin{tabular}{|c|c|c|c|c|c|c|c|}
\hline & & \multicolumn{4}{|c|}{$\begin{array}{l}\text { Distribution of } \\
\text { answers }\end{array}$} & $\mathbf{M}$ & $\mathbf{p}$ \\
\hline $\mathbf{N}$ & Factors & A & B & $\mathrm{C}$ & $\mathrm{D}$ & & \\
\hline 1 & $\begin{array}{l}\text { Maintaining health and increasing labor } \\
\text { productivity }\end{array}$ & 0 & 1 & 15 & 36 & 3.63 & 0.01 \\
\hline 2 & $\begin{array}{l}\text { Reduction of the overall construction } \\
\text { budget }\end{array}$ & 0 & 3 & 14 & 35 & 3.61 & 0.01 \\
\hline 3 & $\begin{array}{l}\begin{array}{l}\text { Reducing the cost } \\
\text { operations }\end{array}\end{array}$ & 0 & 2 & 17 & 33 & 3.60 & 0.01 \\
\hline 4 & $\begin{array}{l}\text { Market advantages (free access to the } \\
\text { market and variety of products) }\end{array}$ & 1 & 3 & 19 & 29 & 3.46 & 0.01 \\
\hline 5 & Job satisfaction & 2 & 4 & 14 & 32 & 3.46 & 0.01 \\
\hline 6 & Recycling and disposal & 2 & 5 & 27 & 18 & 3.17 & 0.01 \\
\hline 7 & Responsibility risk reduction & 5 & 8 & 24 & 15 & 2.94 & 0.01 \\
\hline 8 & Conservation of natural resources & 0 & 4 & 13 & 35 & 2.92 & 0.01 \\
\hline 9 & Attracting and retaining employees & 4 & 7 & 14 & 27 & 2.71 & \\
\hline
\end{tabular}

Answer options: A - strongly disagree; B - do not agree; C - agree; D - completely agree.

Respondents' opinions on the benefits of green construction are presented using a 4point scale in Table 1: from "strongly disagree" to "completely agree". The mean values and significance level $\mathrm{p}$ are given. The responses received indicate that respondents primarily pointed out such advantages as: maintaining health and increasing labor productivity, reducing the overall construction budget, reducing the cost of individual 
operations, that is, they almost completely agreed with all the advantages of environmental construction.

Factors that impede environmental construction and architecture were identified by the survey, the most important were evaluated in terms of their significance by four points on the Likert scale. Table 2 presents the result, shows the estimates of factors that impede the practice of "green" construction, on a scale of 1 to 4, the range from "insignificant" to "very significant". The mean values $(\mathrm{M})$ were calculated, which can be compared taking into account the significance level p. Economic situation, lack of funding $(\mathrm{M}=3.08)$ showed the highest rating. This is followed by an Adverse environment $(\mathrm{M}=2.90)$, market expectations $(M=2.65)$. This suggests that environmental construction is a relatively new trend that respondents regard as a significant problem in the practical application of green construction.

Table 2. Barriers to green building and architecture.

\begin{tabular}{|c|c|c|c|c|c|c|c|}
\hline & & \multicolumn{4}{|c|}{ Distribution of answers } & $\mathbf{M}$ & $\mathbf{p}$ \\
\hline $\mathbf{N}$ & Factors & $\mathrm{A}$ & $\mathrm{B}$ & $\mathrm{C}$ & $\mathrm{D}$ & & \\
\hline 1 & $\begin{array}{l}\text { Economic situation, lack of } \\
\text { funding }\end{array}$ & 3 & 6 & $7^{2}$ & $6^{1}$ & $.08^{3}$ & 0.01 \\
\hline 2 & Adverse environment & 5 & 3 & $6^{1}$ & $8^{1}$ & $.90^{2}$ & 0.01 \\
\hline 3 & Market expectations & 5 & $9^{1}$ & $7^{1}$ & 1 & $.65^{2}$ & 0.01 \\
\hline 4 & $\begin{array}{l}\text { Designers and builders do not seek } \\
\text { to complicate their work }\end{array}$ & 9 & 9 & $4^{1}$ & $0^{1}$ & $\begin{array}{l}2 \\
.48\end{array}$ & 0.01 \\
\hline 5 & Lack of awareness & 3 & $0^{1}$ & $6^{2}$ & $3^{1}$ & $.36^{2}$ & 0.01 \\
\hline 6 & Lack of professionals & $5^{1}$ & $9^{1}$ & 1 & 7 & $.29^{2}$ & 0.01 \\
\hline 7 & Lack of technical tools & $4^{1}$ & $3^{2}$ & 1 & 4 & .2 & 0.01 \\
\hline
\end{tabular}

Answer Options: A - not significant; $\mathrm{B}$ - not too significant; $\mathrm{C}$ - has a value; $\mathrm{D}$ - of very significant.

The study found the following.

Many respondents demonstrated an understanding of sustainable development issues, although they did not always provide extended arguments for this. Their responses were influenced by a number of factors, including: 1) limited space for answers; 2) the nature of the questions asked; 3 ) the fact that this activity is not taken into account in the assessment procedures; 4) it was an atypical topic that respondents had not previously studied in detail during the training program.

1. Conditions for "green" construction in our country exist. - The majority of respondents $(95 \%)$ did not participate in the development of environmental projects.

2. There is a general opinion that the criterion for choosing a construction site for the construction of ecological buildings is not met, $84 \%$ of respondents indicated that they did not participate in any rehabilitation of the construction site for environmental construction, while only $16 \%$ of respondents indicated that they participated in site restoration for construction.

3. The problems that most impede the practice of environmental construction include the economic situation, lack of funding $(\mathrm{M}=3.08)$, lack of favorable conditions $(\mathrm{M}=2.90)$ and economic situation $(\mathrm{M}=2.90)$. The lack of awareness $(\mathrm{M}=2.36)$ occupies an intermediate position among the factors that impede the practice of ecological construction. 
4. All the advantages indicated in the questionnaire were considered as very important, since they have a rating higher than the average score. The most important advantages: Maintaining health and performance $(\mathrm{M}=3.63)$, further - Reduction of the overall construction budget $(\mathrm{M}=3.61)$, Reducing the cost of individual operations $(\mathrm{M}=$ 3.60), as well as Market advantages (3.46) and Job satisfaction (3.46).

An oral interview was conducted with some masters in an attempt to clarify the controversial answers related to the practice of green building, as well as the benefits derived from the this practice. In addition, questions that were not adequately covered by the questionnaire were partially included in the interview.

Problems of practical application of ecological construction and architecture were identified and formulated after the survey.

1. The lack of a favorable external environment. The results of the study show that there is no external environment in the form of policy, legislation or any form of incentive for the practice of green building. Compared with what happens in a developed nation, in which the government set an example - through the construction of some kind of public building, using the concept green building.

2. Uncertain economic situation: the private sector has a narrow market base and the state construction industry relies excessively on the government for work, whose work orders fluctuate with income. This has led to fluctuations in construction work, which impede long-term strategic planning and, in turn, impede access to investment capital. Delays in interim and final payments, as well as the onerous contractual conditions faced by construction companies, constitute a huge limitation on the industry.

3. Lack of comprehensive research: most of the research in construction technology and planning is not carried out as part of a holistic approach. Institutions, development agencies and other organizations conduct research and deal with each problem individually, regardless of other issues with which they are associated.

4. Technological barriers: technological dependence interferes with the autonomous development of our own technology. We need knowledge and technologies that are adapted to the natural resources of the country.

5. The problem of accountability and transparency: the lack of transparency in management goes into a situation where the construction industry becomes a breeding ground for unfair practices, especially corruption during the preparation and conduct of auctions / tenders and contracting practices, as well as during the construction process. Overvaluation of the contract and remuneration based on kickback, patronage and favoritism, and not on the basis of the contractor's reliable technological know-how.

6. Lack of interest in the issue of sustainable development: general lack of interest in the issue of sustainable development in the construction industry indicated by its customers and other interested parties. This is embodied in practice in different ways by various stakeholders, such as: a) leaders: issues of environmental sustainable development rarely constitute a major state distinguishing feature of the agenda of companies, political parties; b) local authorities: issues of sustainable development never form any requirements for the coordination of plans, land use or the division of land.

\section{Conclusions and recommendations}

This study attempted to measure the perceptions of future graduate professionals in the construction of practices of green building and architecture. The concept of sustainable development in construction, the role of green building and architecture, the role of each involved professional, the processes and advantages associated with green building and architecture were carefully considered. Appropriate criteria have been proposed so that 
buildings and structures can be qualified as green. Based on the results, the following conclusions were made.

The most important activities to achieve sustainable development are the ecological restoration of urban landscapes and their components, the greening of the city's economic activities, and the greening of the needs of urban residents.

Green building is little practiced in Russia; there is no favorable external environment, legislation and policies regarding green building. The general perception of green building by all groups of respondents showed that most professionals, realizing the new trend (green building) and the huge benefits received from it, consider green building as the basis for attractive residential buildings and the preservation of natural resources, care for the health of urban residents. However, the general public is not fully aware of it, the level of awareness of green building and architecture remains low.

In the current curriculum of some disciplines of higher education there is no corresponding methodological support for green building and architecture.

Based on the results obtained in this study, the following can be recommended.

1. Develop and implement competencies related to green construction in the Federal State Educational Standards of Higher Education.

2. Architects should take a more integrated approach to design and appreciate the importance of green building [16].

3. Manufacturers of building materials should use life cycle considerations as the basis for product development and should work with architects to create new building materials by recycling old ones. In addition, it is necessary to establish cooperation with research firms, providing them with funds for research, development and implementation [17].

4. State bodies, large corporations, self-regulatory organizations should set an example through the construction of green buildings and structures during the construction of large public buildings and develop an economic incentive mechanism for those wishing to build green buildings.

5. It is necessary to continue research on green building and architecture.

\section{References}

1. A. P. C. Chan, A. Darko, E. E. Ameyaw, Strateg. Promot. Gr. Build. Tech. Adop. Constr. Ind. Inter. Stud. Sustain. 9, 969 (2017)

2. C. J. Kilbert, Sustainable Construction: green building design and deliver (2005)

3. S. V. Kornienko, E. D. Popova, "Green” constr. Rus. Abr. Constr. Uniq. Build. Struct. 4 (55), 67-93 (2017)

4. R. Ruparathna, K. Hewage, J. Clean. Prod. 109, 305-314 (2015)

5. S. N. Bobylev, S. V. Solovyeva, Sustain. Develop. Goals Fut. Rus. Stud. Rus. Econ. Develop. 28, 259-265 (2017)

6. V. Logvinov, From "green construction" to nature-integrated architecture. The principle of the interconnection of environments, Construction expert (2017), https://ardexpert.ru/article/8688

7. M. Pitt, M. Tucker, M. Riley, J. Longden, Int. J. Constr. Archit. Innov. 9, 201-224 (2009)

8. S. Vierra, Green Building Standards and Certification Systems, https://www.wbdg.org/resources/green-building-standards-and-certification-systems

9. N. R. Vechi, A. L. Gallardo, C. Teixeira, Syst. Manag. 11 (1), 17-30 (2016) 
10. G. Fernández-Sánchez, F. Rodríguez-López, Method. Ident. Sustain. Indicat. Constr. Proj. Manag. 10, 1193-1201 (2010)

11. S. Holloway, K. Parrish, Contrac. Role Sustain. Indust. Inst. Civil Engin. Engineering Sustain. 168 (2), 53-60, (2015)

12. U. Berardi, Build. Ener. Consum. US, EU, BRIC Countr. Proc. Eng. 118, 128-136 (2015)

13. O.V. Blizniuk, Constr. Econ. 2, 29-36 (2012)

14. N. I. Borisova, A. V. Taranova, Modern Manag. Technol. 3 (63), (2006) https://sovman.ru/article/6304/

15. A. A. Muravyova, O. N. Oleinikova, Educ. Sci. 1 (8), 23-37 (2016)

16. M. Meerovich, The Strategy of Spatial Development of Russia: modernity and the legacy of the Soviet Settlement Doctrine, MATEC Web of Conferences 212, 01001 (2018)

17. N. V. Danilova, S. A. Karimova, Envir. Imp. Asses. Implem. Inter. Leg. Require. Rus. Legis. Inter. law 2, $110-121$ (2015) 